\title{
CARACTERIZAÇÃO DE GRANOLAS COMERCIAIS ${ }^{1}$
}

\author{
Graziele GRANADA², Vanessa ROSA ${ }^{3}$, Rui ZAMBIAZI ${ }^{4, *}$, Paulo KOETZ ${ }^{5}$
}

\section{RESUMO}

Foram coletadas no comércio local 35 unidades de granolas, das quais foram formadas 7 amostras compostas, de forma que cada amostra representasse uma marca. Avaliou-se a ocorrência de Salmonella spp., contagem de Staphylococcus aureus, coliformes totais, fecais e contagem de mofos e leveduras. Foram realizadas, também as análises de umidade, lipídios, proteina bruta, fibra bruta, cinzas, $\mathrm{pH}$, acidez, açúcares totais, açúcares redutores, além da determinação do teor de carboidratos e do valor calórico. Constatou-se que três amostras apresentaram-se fora dos padrões estabelecidos pela legislação vigente. Quanto aos parâmetros físico-quimicos, verificou-se que as amostras apresentaram grande variação nas suas composições.

Palavras-chave: Granola; mofos e leveduras; umidade; $\mathrm{pH}$.

\section{SUMMARY}

CHARACTERIZATION OF COMMERCIAL GRANOLAS. Thirty five samples of granolas were collected in the local market, and they were distributed in a way that each sample could represent one brand. It was evaluated the occurrence of Salmonella spp., Staphylococcus aureus, coliform bacteria, molds and yeasts. Still, the moisture, lipid, protein, fibers, ashes, pH values, acidity, total sugar, reduced sugar, carbohydrates, and total caloric content were evaluated. It was verified that three samples presented incompatible results with the correspondent legislation. About the physic and chemical parameters, it was verified that the samples showed a big variation in their composition.

Keywords: granola; molds and yeasts; moisture; $\mathrm{pH}$.

\section{1 - INTRODUÇÃO}

A crescente demanda no consumo de alimentos ricos em fibras é fundamentada no fato de que as fibras atuam aumentando o volume do bolo fecal, diminuindo o desconforto causado pelo sintoma de constipação intestinal [22]; e, também, pelo fato comprovado que dietas ricas em fibras reduzem o risco de doenças cardiovasculares [12]. Além disso, reduz os níveis de insulina no sangue e baixa a concentração de lipídios em pacientes com diabetes insulino dependente [10]. Dentre estes alimentos, destaca-se a granola, que é um produto alimentar constituído por uma mistura de frutas secas, grãos de cereais e sementes oleaginosas, tais como o amendoim e castanha-do-pará [28]. Embora seja um alimento nutritivo, rico em fibras, carboidratos e lipídios, possui baixo teor de proteínas, apresentando-se como produto energético, e de sabor agradável [29].

Entre as matérias-primas utilizadas em sua produção, pode-se citar a linhaça, a qual até pouco tempo somente era usada em rações para animais; também flocos de milho fazem parte da formulação de algumas granolas; assim como o amendoim, o milho já foi objeto de estudos onde identificou-se a presença de aflatoxinas,

\footnotetext{
${ }^{1}$ Recebido para publicação em 10/09/2001. Aceito para publicação em 20/05/2002.

${ }^{2}$ Depto de Ciência e Tecnologia Agroindustrial/UFPEL. E-mail: graziele@ufpel.tche.br

3 Depto. de Quimica de Alimentos/UFPEL. E-mail: vanessarosa_rs@hotmail.com

4 Departamento de Ciência dos Alimentos/UFPEL E-mail: zambiazi@ufpel.tche.br

${ }^{5}$ Departamento de Ciência e Tecnologia Agroindustrial/UFPEL.

* A quem a correspondência deve ser enviada.
}

metabólitos secundários produzidos por Aspergilus flavus e Aspergilus parasiticus [26]. As aflatoxinas apresentam atividade mutagênica, carcinogênica e teratogênica em animais de laboratório [6, 7, 11,34], e quando ingeridas continuadamente em doses elevadas, podem causar principalmente câncer hepático no homem [1].

O desenvolvimento microbiano nos alimentos é condicionado por diversos fatores extrínsecos, como temperatura e umidade relativa, e por fatores intrinsecos, sendo os principais a atividade de água, o $\mathrm{pH}$, o potencial redox e a composição do alimento, além da condição física e sanitária do grão [23, 32].

$\mathrm{O}$ alimento quando processado a partir de matériaprima de boa qualidade, manipulado e armazenado sob boas práticas de higiene, é fonte de saúde imprescindivel ao ser humano. Entretanto, quando tais medidas não são consideradas, pode tornar-se veículo de diversos microrganismos patogênicos capazes de causar toxinfecções alimentares [9, 16].

No Brasil, os órgãos governamentais responsáveis pela saúde pública têm registrado vários surtos envolvendo alimentos com elevada contaminação microbiana [24].

A Resolução RDC nํㅜ 12, de 12 de janeiro de 2001 [4], estabelece, para os produtos pesquisados neste estudo, os seguintes parâmetros: ausência de Salmonella spp. em $25 \mathrm{~g}$ de amostra; índices máximos de $5.10^{2} \cdot \mathrm{g}^{-1} \mathrm{e}$ $10^{2} \cdot \mathrm{g}^{-1}$ para coliformes e Staphylococcus aureus, respectivamente.

Dentre as enfermidades transmitidas por alimentos, aquelas causadas por Staphylococcus aureus e Salmonella spp. têm causado, com elevada freqüência, transtornos à população [9]. 
A intoxicação alimentar provocada pelo Staphylococcus aureus é devida à ingestão de alimentos contendo enterotoxinas produzidas e liberadas pela bactéria durante a sua multiplicação. Niveis de enterotoxina que variam de 0,01 a $0,4 \mu \mathrm{g}$ por grama de alimento já são suficientes para provocar intoxicações [25].

Salmonella é um microrganismo causador de infecção alimentar, tem origem entérica e, em função de sua capacidade de disseminação no meio ambiente, pode ser isolado de diferentes fontes, como carnes, pescados, verduras e ovos. Pode, ainda, ser veiculado pelo próprio homem, neste caso na condição de portador assintomático. É, em todo o mundo, um dos microrganismos mais freqüentemente envolvidos em surtos de doenças de origem alimentar [20].

Outros agentes freqüentemente encontrados em alimentos são os coliformes fecais, que são microrganismos utilizados para monitorar as condições higiênicosanitárias do processamento e armazenamento, além de mostrarem o potencial de deterioração de um alimento; números elevados de coliformes, podem apontar também, deficiências no tratamento térmico, já que não são formadores de esporos. A finalidade desta análise é indicar a provável presença de microrganismos de origem entérica [15].

O desenvolvimento de mofos e leveduras é mais freqüente em alimentos que apresentam elevada concentração de sólidos solúveis; portanto, com baixa atividade de água. Também destaca-se em alimentos, cujo $\mathrm{pH}$ encontra-se na faixa de 2,0 a 8,5 , abrangendo uma quantidade expressiva de alimentos [8].

Mofos e leveduras podem utilizar uma variedade de substratos e causar alterações nos alimentos, como a elevação de $\mathrm{pH}$, que favorece o crescimento de bactérias patogênicas, além da produção de odores, sabores e colorações indesejáveis [33].

A granola é um produto que vem apresentando crescente consumo, principalmente em razão de suas propriedades funcionais. No entanto ainda são insipientes as informações sobre este alimento [13]. Porém, em função de ser um produto resultante da mistura de cereais e sementes oleaginosas, a granola está sujeita ao desenvolvimento de mofos e leveduras. A presença destes microrganismos é importante para avaliar a qualidade da matéria-prima utilizada, condições de processamento, e de estocagem destes produtos [17]. Além disso, grande parte das granolas contém açúcar em sua composição; e o açúcar, quando contaminado, pode contribuir para a elevação da população de microrganismos presentes no produto final [18].

Considerando-se a quase inexistência de pesquisas sobre características nutricionais deste alimento, bem como o risco de contaminação microbiológica decorrente da sua composição, este trabalho objetivou avaliar a qualidade de granolas comercializadas na cidade de Pelotas/RS, a partir de análises físico-químicas e microbiológicas.

\section{2 - MATERIAL E MÉTODOS}

\section{1 - Obtenção das amostras}

Foram obtidas no comércio varejista de Pelotas-RS, trinta e cinco (35) pacotes de granolas, de 7 diferentes marcas comerciais, todas dentro do prazo de validade.

A qualidade das granolas foi avaliada pelas análises microbiológicas e físico-químicas, sendo para isto feitas amostras compostas, de modo que cada amostra representasse uma marca.

\section{2 - Análises microbiológicas}

Realizaram-se as análises de pesquisa de Salmonella spp., contagem de Staphylococcus aureus, determinação do Número Mais Provável de coliformes totais e fecais, e contagem de mofos e leveduras. Estas análises foram feitas seguindo os procedimentos descritos pelo Compendium of Methods for the Examination of Foods [33].

\section{3 - Análises físico-quimicas}

Foram realizadas as análises de umidade, lipídios, proteína bruta, fibra bruta, cinzas, $\mathrm{pH}$, acidez, açúcares totais e açúcares redutores, todos em triplicata, de acordo com os procedimentos descritos pelas Normas Analíticas do INSTITUTO ADOLFO LUTZ [19]. Os carboidratos foram calculados por diferença [100 - (umidade + lipídios + proteínas + fibras + cinzas)], e o valor calórico foi determinado pelo cálculo da energia liberada pelos componentes alimentares, ambos segundo a ResoluçãoRDC no 40 de 21 de março de 2001 [5].

\section{4 - Análise estatística}

Todos os resultados foram avaliados pela análise de variância ( ANOVA), e os valores que mostraram diferença significativa de médias, foram complementados com o teste de Duncan, ao nível de 5\% de probabilidade, pelo programa Statistica 5.1 [31].

\section{3 - RESULTADOS E DISCUSSÕES}

Das amostras de granolas coletadas nos estabelecimentos de Pelotas-RS os resultados mostraram baixa incidência de contaminação por Salmonella spp., Sthaphylococcus aureus e por coliformes fecais. Esses dados podem ser observados na Tabela 1 .

Pelos resultados da Tabela 1 verifica-se que, em termos de Salmonella spp. e Staphylococcus aureus, todas as amostras de granola mostraram-se satisfatórias, atendendo a legislação vigente [4] a qual estabelece que deve haver ausência de Salmonella em $25 \mathrm{~g}$ de produto, e o máximo de $10^{3} \mathrm{UFC}^{-1}{ }^{-1}$ para Staphylococcus aureus.

Em pesquisa sobre a qualidade microbiológica de um tipo de granola elaborada na Escola de Nutrição - UFBA, FURTUNATO et al. [12] também constataram ausência de Salmonella spp e Staphylococcus aureus. 
TABELA 1. Características microbiológicas das granolas coletados em Pelotas/RS

\begin{tabular}{|c|c|c|c|c|c|c|c|}
\hline \multirow[b]{2}{*}{ ANÁLISES } & \multicolumn{7}{|c|}{ AMOSTRAS } \\
\hline & 1 & 2 & 3 & 4 & 5 & 6 & 7 \\
\hline $\begin{array}{l}\text { Coliformes totais } \\
\left.\left(\text { NMP }^{-1}\right)^{-1}\right)\end{array}$ & $9,2.10^{2}$ & $4,3.10^{2}$ & $<3$ & $23.10^{2}$ & $9,2.10^{2}$ & $<3$ & $4.10^{2}$ \\
\hline $\begin{array}{l}\text { Coliformes Fecais } \\
\left(\text { NMP. } g^{-1}\right)\end{array}$ & $<3$ & $<3$ & $<3$ & $<3$ & $<3$ & $<3$ & $<3$ \\
\hline $\begin{array}{l}\text { Mofos e Leveduras } \\
\left(\text { UFC. } g^{-1}\right)\end{array}$ & $23.10^{6}$ & $23.10^{6}$ & $27.10^{6}$ & $33.10^{6}$ & $32.10^{6}$ & $37.10^{5}$ & $12.10^{4}$ \\
\hline $\begin{array}{l}\text { Staphylococcus } \\
\text { aureus (UFC. } \mathrm{g}^{-1} \text { ) }\end{array}$ & $<100$ & $<100$ & $<100$ & $<100$ & $<100$ & $<100$ & $<100$ \\
\hline $\begin{array}{l}\text { Salmonella spp } \\
(\mathrm{em} 25 \mathrm{~g})\end{array}$ & Ausência & Ausência & Ausência & Ausência & Ausência & Ausência & Ausência \\
\hline
\end{tabular}

A ausência de matéria-prima de origem animal em granolas, reduz a probabilidade de contaminação por Salmonella; no entanto, granolas que contêm em sua composição ingredientes tão diversos, como o amendoim, coco, nozes e passas de frutas, que podem estar contaminados com esses microrganismos.

$\mathrm{Na}$ pesquisa de coliformes fecais, os resultados foram satisfatórios, já que todas as amostras apresentaram contaminação inferior a $3 \mathrm{NMP} \cdot \mathrm{g}^{-1}$, confirmando que não ocorreu a presença de microrganismos de origem entérica.

Os resultados obtidos na análise de coliformes totais para as amostras 1, 4 e 5 encontram-se com valores acima dos permitidos pela legislação vigente, a qual estabelece níveis máximos de $5.10^{2} \mathrm{NMP}^{-1}{ }^{-1}$, tornando o produto inaceitável para o consumo. As demais amostras enquadram-se dentro do limite estabelecido pela legislação.

Tendo em vista que este estudo teve início quando a legislação em vigor era a Portaria 451, do Ministério da Saúde, a qual não designava uma categoria específica para granolas, portanto não havia um elenco de análises como da atual portaria. Desta forma não foi realizada a análise de Bacillus Cereus, que atualmente é exigida pela legislação.

Embora a Resolução RDC no 12 , de 12 de janeiro de 2001 não faça referência a contagem de mofos e leveduras para granolas, CAMEL et al. [7] observaram que os produtos de amendoim que apresentaram maiores niveis de contaminação são os industrializados artesanalmente, e como grande parte das granolas analisadas eram artesanais, e continham amendoim em sua composição, fez-se indispensável a pesquisa destes microrganismos, visto que os fungos além de serem agentes causadores de alterações físicas e químicas em grãos armazenados, podem produzir micotoxinas, inviabilizando seu uso ou de seus subprodutos como alimento para o consumo humano ou animal [2].

Segundo a Agência Nacional de Vigilância (ANVISA), medidas cautelares objetivam avaliar a qualidade de produtos comercializados e evitar que a população tenha acesso ao consumo de substâncias potencialmente tóxicas. Salienta-se ainda que, somente um rigoroso controle de qualidade sobre a matéria-prima e sobre a armazenagem dos alimentos pode garantir a oferta de produtos que atendam aos padrões sanitários vigentes [1].
Os resultados microbiológicos neste estudo indicaram presença entre $12.10^{4}$ e $33.10^{6} \mathrm{UFC} / \mathrm{g}$ de mofos e leveduras nas amostras avaliadas. Esta alta contagem pode ter sido favorecida pela faixa de $\mathrm{pH}$ encontrada nos produtos, entre 4,84 e 5,54, faixa na qual estes microrganismos se multiplicam facilmente.

Embora o teor de umidade de 11-13\% em cereais em geral seja preconizado como adequado para inibir o desenvolvimento de mofos e leveduras em condições ambientais, os teores inferiores de umidade apresentados neste estudo (5,23 a 9,17\%), não foram o suficiente para inibir o desenvolvimento destes microrganismos nas granolas, confirmando estudos previamente realizados por JAY [21], o que talvez seja atribuído a diversidade de componentes presentes neste tipo de produto.

O desenvolvimento dos mofos e leveduras pode também ter sido favorecido pela dificuldade de crescimento de bactérias, em virtude da pressão seletiva exercida pela elevada taxa de açúcar e pela baixa atividade de água no substrato, devido a possibilidade de desenvolvimento de mofos e leveduras em atividade de água inferior ao necessário para o desenvolvimento de bactérias [27, 33].

Na Tabela 2 são apresentados os resultados obtidos nas análises físico-químicas das granolas.

TABELA 2. Características físico-químicas das granolas coletados em Pelotas/RS

\begin{tabular}{|c|c|c|c|c|c|c|c|}
\hline \multirow[b]{2}{*}{ ANÁLISES } & \multicolumn{6}{|c|}{ AMOSTRAS } & \multirow[b]{2}{*}{7} \\
\hline & 1 & 2 & 3 & 4 & 5 & 6 & \\
\hline Umidade (\%) & $6,67 a$ & $5,23 b$ & $8,81 \mathrm{c}$ & $8,27 d$ & $9,17 \mathrm{c}$ & $7,70 \mathrm{e}$ & $7,66 \mathrm{e}$ \\
\hline Lipídios (\%) & $12,32 a$ & $6,56 b$ & $5,00 c$ & $14,40 \mathrm{~d}$ & $5,73 e$ & $10,27 f$ & $5,18 \mathrm{~g}$ \\
\hline Proteína bruta (\%) & $10,81 a$ & $12,34 b$ & $10,23 \mathrm{c}$ & $11,49 d$ & $9,40 \mathrm{e}$ & $12,72 f$ & $6,40 \mathrm{~g}$ \\
\hline Fibra bruta (\%) & $1,81 \mathrm{a}$ & $2,31 b$ & $2,13 c$ & $1,82 a$ & $1,58 d$ & $0,83 e$ & $0,31 f$ \\
\hline Cinzas (\%) & $1,99 a$ & $2,06^{a} b$ & $1,98 \mathrm{a}$ & $2,09 b$ & $1,79 \mathrm{c}$ & $1,69 d$ & $1,69 d$ \\
\hline $\mathrm{pH}$ & $5,19 a$ & $5,54 \mathrm{~b}$ & $4,84 c$ & $5,33 d$ & $4,98 \mathrm{e}$ & $5,28 f$ & $5,20 a$ \\
\hline Acidez (\%) & $0,40 a$ & $0,34 b$ & $0,34 b$ & $0,28 c$ & $0,32 b$ & $0,25 c$ & $0,14 d$ \\
\hline $\begin{array}{l}\text { Açúcares } \\
\text { Totais (\%) }\end{array}$ & $22,00 a$ & $23,19 b$ & $20,93 c$ & $10,89 d$ & $17,46 e$ & $11,15 f$ & $31,48 \mathrm{~g}$ \\
\hline $\begin{array}{l}\text { Açúcares } \\
\text { redutores (\%) }\end{array}$ & $15,14 a$ & $10,19 b$ & $19,07 \mathrm{c}$ & $7,84 d$ & $11,33 \mathrm{e}$ & $10,85 f$ & $27,28 \mathrm{~g}$ \\
\hline Carboidratos (\%) & $66,40 a$ & $71,50 \mathrm{~b}$ & $71,85 \mathrm{c}$ & $61,93 d$ & $72,33 e$ & $67,39 f$ & $78,76 \mathrm{~g}$ \\
\hline $\begin{array}{l}\text { Calorias } \\
\text { (Kcal/100g) }\end{array}$ & 419,72 & 394,40 & 373,32 & 423,28 & 378,49 & 410,47 & 387,26 \\
\hline
\end{tabular}

Letras diferentes na mesma linha evidenciam diferença significativa a nível de $5 \%$ de probabilidade pelo teste de Duncan $(\mathrm{p}<0,05)$.

Pelos dados apresentados na Tabela 2, observou-se que não houve diferença significativa de umidade apenas entre as amostras 3 e 5 , e as amostras 6 e 7 . Também observou-se que as amostras com os maiores teores de umidade (amostras 3, 4 e 5), apresentaram as maiores contagens de mofos e leveduras (Tabela 1). A variação de umidade pode ter sido influenciada pela embalagem, visto que as amostras que não apresentaram diferenças significativas, estavam contidas em embalagens semelhantes. Estudos similares de SIMÕES et al. [29], em pesquisa realizada em granolas elaboradas pela Universidade Federal da Bahia, também detectaram baixos teores de umidade.

Verificou-se que todas as amostras diferiram significativamente entre si no conteúdo de lipídios, proteína 
bruta, carboidratos, açúcares totais e açúcares redutores. Essas diferenças estão relacionadas com a diversidade de ingredientes da composição dos diferentes tipos de granolas. No entanto, observou-se que as amostras 1, 4 e 6 apresentaram os valores mais elevados de lipídios, e entre os mais altos de proteínas, provavelmente devido a presença de linhaça em suas formulações; este componente apresenta na sua composição centesimal $45,98 \%$ de lipídios e $20,46 \%$ de proteínas [3], o que proporciona um acréscimo do valor energético na formulação final das granolas.

Os resultados obtidos na análise de fibra bruta não diferiram significativamente para as amostras 1 e 4, sendo que o restante das amostras apresentou diferenças significativas em seu conteúdo. A quantidade de fibras nas amostras analisadas neste estudo foi bem inferior à quantidade de fibras presente em uma marca comercial de granola (4g/100g) produzida na Europa [14], possivelmente devido à maior diversidade de matéria-prima na granola européia.

Nas granolas analisadas encontrou-se percentuais de carboidratos entre 61,93\% (amostra 4) a 78,76\% (amostra 7), o que relacionou-se ao menor conteúdo de açúcares totais na amostra 4, e o maior conteúdo na amostra 7 , respectivamente. Os percentuais de carboidratos também se relacionaram com o desenvolvimento de mofos e leveduras, onde a amostra 4 (com o menor conteúdo em carboidratos) apresentou o maior nivel de mofos e leveduras, e a amostra 7 (com o maior conteúdo em carboidratos) apresentou menor índice de desenvolvimento de mofos e leveduras, provavelmente devido a influencia do conteúdo dos carboidratos na atividade de água, e conseqüentemente, na disponibilidade de água nas granolas. $\mathrm{Na}$ amostra 7 fica evidente o elevado teor de açúcares, tanto totais quanto redutores, em relação as demais amostras, o que é explicado pela maior adição de mel nesta formulação.

Os valores encontrados na análise de cinzas não diferiram significativamente entre as amostras 1, 2 e 3, ocorrendo o mesmo para as amostras 3 e 4 e para as amostras 6 e 7 . Somente a amostra 5 não apresentou semelhança significativa com qualquer uma das amostras, embora todas apresentaram o teor de cinzas entre 1,69 e $2,09 \%$, o que indica uma composição no conteúdo total de matéria inorgânica muito similar entre as amostras.

Verificou-se que o pH situou-se entre 4,84 a 5,54, demonstrando que esses produtos enquadram-se na faixa de $\mathrm{pH}(2,0$ e 8,5$)$ em que os mofos e leveduras se multiplicam com facilidade [30]. Observou-se que somente as amostras 1 e 7 não apresentaram diferenças significativas entre si.

Com relação a acidez, constatou-se que as amostras 1 e 3; 2 e 5; 4 e 6, são respectivamente iguais entre si; e a amostra 7 diferiu significativamente das demais amostras. Observou-se que as pequenas variações na acidez não estiveram associadas com as variações de $\mathrm{pH}$, e também parecem não ter influenciado na presença de mofos e leveduras nas amostras.

\section{4 - CONCLUSÕES}

Nas análises microbiológicas de Salmonella spp. e Staphylococcus aureus, nenhuma das amostras apresentou contagens superiores às permitidas pela legislação vigente. Entretanto, com relação ao Número Mais Provável de coliformes totais, três amostras apresentaram-se fora dos padrões estabelecidos, sendo classificadas "como impróprias para o consumo". Quanto as características físico-químicas, verificou-se que as amostras apresentaram grande variação nas suas composições, em função da variedade da matérias-primas empregadas neste produto, destacando-se as quantidades de lipídios, proteínas e carboidratos.

\section{5 - REFERÊNCIAS}

[1] ANVISA DIVULGA. On line. Disponivel na Internet: <http:// www.anvisa.org.br/Divulga/notícias / 160201-02htm.> Em: 22 out. 2001.

[2] ARSEGO, O.; RUPOLlO, G.; AFONSO, A. P.; NORA, L. Avaliação fúngica em diferentes métodos de conservação de arroz integral. In: $9^{\circ}$ CONGRESSO DE INICIAÇÃO CIENTÍFICA E $2^{\circ}$ ENCONTRO DA PÓS GRADUAÇÃO UFPEL, FURG, UCPEL, Pelotas - RS, 2000. Resumos ...: Pelotas - RS, v. 2, p.623.

[3] BERNAL-GÓMEZ, M. E.; TORRES, R. P.; MANCINI-FILHO, J. Avaliação da estabilidade oxidativa da linhaça (Linun Usitatissimum L.). In: CONGRESSO BRASILEIRO DE CIÊNCIA E TECNOLOGIA DE ALIMENTOS, 17, Fortaleza-CE, 2000, Resumos... Fortaleza-CE, Sociedade Brasileira de Ciência e Tecnologia de Alimentos, 2000, v. 2, p.5.192.

[4] BRASIL. Ministério da Saúde. Secretaria de Vigilância Sanitária. Resolução RDC n 12 , de 02 de janeiro de 2001. Regulamento técnico sobre os padrões microbiológicos para alimentos. Diário Oficial [da] República Federativa do Brasil, Brasília, n. 7-E, 10 jan. 2001. p. 45 - 53.

[5] BRASIL. Ministério da Saúde. Secretaria de Vigilância Sanitária. Resolução RDC n ${ }^{\circ} 40$, de 21 de março de 2001. Regulamento técnico para rotulagem nutricional obrigatória de alimentos e bebidas embaladas. Diário Oficial [da] República Federativa do Brasil, Brasília, n. 57-E, 22 mar. 2001. p. $22-25$.

[6] BRIGIDO, B. M.; BODOLATO, M. I. C.; FREITAS, U. P. S. Contaminações de amendoim e seus produtos comercializados na região de Campinas - SP., por aflatoxinas durante o ano de 1994. Revista do Instituto Adolfo Lutz v. 55, n.2, p. 80-85, 1995.

[7] CAMEL, M.; NUNES, L.; FAJARDO, D. S.; ALEIXO, J. G. Teor de aflatoxinas em produtos de amendoim comercializados em Pelotas. In: $9^{\circ}$ CONGRESSO DE INICIAÇÃO CIÊNTIFICA E $2^{\circ}$ ENCONTRO DA PÓS GRADUAÇÃO - UFPEL, FURG, UCPEL, Pelotas - RS, 2000. Resumos ...: Pelotas - RS, v. 2, p.642.

[8] CORLETT Jr., P. A., BROWN, M. H. pH and acidity. In: INTERNATIONAL COMMISSION ON MICROBIOLOGICAL SPECIFICATIONS FOR FOODS. Microbial ecology of foods: factors affecting life and death of microrganisms. New York: Academic Press, v. 1, p.92-111, 1980.

[9] DIAS, R. S.; CARMO, L. S.; SILVA, M. C. C. Surtos de toxinfecção alimentar causado pela ação simultânea de enterotoxina estafilocócica e salmonella enteritidis. Revista do Instituto Adolfo Lutz, v. 58, n. 1, p. 7-11, 1999.

[10] Dieta muito rica em fibras ajuda diabéticos a controlar glicose. On line. Disponivel na Internet: <http:// 
www.globo.com/notícias/arquivo/saúde/20000516 / 4kdlmy.htm> Em: 4 mai. 2001.

[11] FURIANI, R. P. Z.; SOARES, L. M. V. Survey of aflatoxins, ochratoxin A, zearalenone, and sterigmatocystin in tree nuts commercialized in Campinas, São Paulo. Ciência e Tecnologia de Alimentos, v. 16, n. 3, p. 238-240, 1996.

[12] FURTUNATO, D. M. N.; MAZZA, R. P. D.; SANTOS, N. S.; SILVA, M. Determinação da qualidade microbiológica da granola produzida na escola de nutrição - UFBA. In: CONGRESSO BRASILEIRO DE MICROBIOLOGIA, 20, 1999, Salvador-Ba. Resumos ... Salvador-Ba: Sociedade Brasileira de Microbiologia, 1999, p. 386.

[13] GRANADA, G.; ROSA, V.; ZAMBIAZI, R.; KOETZ, P. Composição centesimal de granolas comercializadas em Pelotas. In: ENCONTRO DE DEBATES SOBRE O ENSINO EM QUÍMICA, 20, 2000 Porto Alegre. Resumos... Porto Alegre, RS: Pontificia Universidade Católica, 2000. p. 73.

[14] GRANOLA. On line. Disponivel na Internet: <http://www. vitamins-etc.com/rec_description.asp?rID=iy0t0q5y0bl.> Em: 4 mai. 2001.

[15] HAJDENWURCEL, J. R. Atlas de microbiologia de alimentos. São Paulo, v.1, 1998.

[16] HILUY, D. J.; ARAÚJO, R. E. S.; NORONHA, M. D. Perfil da qualidade higiênico-sanitária de alimentos comercializados no município de Fortaleza, CE. In: CONGRESSO BRASILEIRO DE CIÊNCIA E TECNOLOGIA DE ALIMENTOS, 17, Fortaleza-CE, 2000, Resumos... Fortaleza-CE, Sociedade Brasileira de Ciência e Tecnologia de Alimentos, 2000, v. 1, p.3.173.

[17] HOFFMANN, F.L.; GARCIA-CRUZ, C. H.; VINTURIM, T. M.; PAZZOTI, G. S. O. Qualidade microbiológica de diferentes marcas comerciais de suco fresco de laranja integral. Boletim do CEPPA, Curitiba, v. 16, n. 1, p. 99 106, jan/jun. 1998.

[18] HOFFMANN, F.L.; GARCIA-CRUZ, C. H.; VINTURIM, T. M Avaliação das características microbiológicas de amostras de açúcar refinado de diferentes marcas comerciais obtidas na região de São José de Rio Preto - S P. Boletim do CEPPA, Curitiba, v. 10, n. 1, p. $75-82$, jan/jun. 1992.

[19] INSTITUTO ADOLFO LUTZ. Normas analiticas do Instituto Adolfo Lutz. 2. ed. São Paulo, 1985. 371 p.

[20] JAKOBI, M.; BUZZO, A. A.; RISTORI, C. A.; TAVECHIO, A. T.; SAKUMA, H.; PAULA, A. M. R.; GELLI, D. S. Observações laboratoriais sobre surtos alimentares de salmonella sp. Ocorridos na grande São Paulo, no período de 1994 a 1997, Revista do Instituto Adolfo Lutz. v. 58, n. 1, p. 47- 51, 1999.

[21] JAY, M. J. Microbiologia moderna de los alimentos. 3 ed. España: Acribia, 1994. 804 p.
[22] KRAUSE, M. V.; MAHAN, L. K. Alimentos, nutrição e dietoterapia. 7 ed. São Paulo: Roca, 1991. 981 p.

[23] MÁRCIA, B. A., LAZZARI, F. A., Monitoramento de fungos em milho em grão, grits e fubá. Ciência e Tecnologia de Alimentos, v. 18, n. 4, p. 363-367, 1998.

[24] OLIVEIRA, T. C.; HIROOKA, E. Y. Atualidades sobre a detecção de enterotoxinas estafilocócicas. Boletim SBCTA. Campinas, v 30, n. 2, p. 121-131, jul./dez. 1996.

[25] PASSOS, M. H. C.R.; KUAYE, A.Y. Relato de surto de intoxicação alimentar provocada por consumo de bolo contaminado por staphylococcus aureus - importância da higiene dos manipuladores e condições de conservação do alimento na prevenção da doença. Revista do Instituto Adolfo Lutz, v. 56, n. 1, p. 71- 76, 1996.

[26] PRADO, G., MARTINS VIERIRA, M. B. C., OLIVEIRA, M. S. Contaminação fungica e niveis de aflatoxinas em amendoim recém-colhido cultivado em dois tipos de solo. Ciência e Tecnologia de Alimentos, v.16, n. 1, p. 72-74, 1996.

[27] REITER, M.G.R.; CAVALHERI, N.; SCOLARO, C. Determinação de shelf life de biscoitos amanteigados artesanais. In: CONGRESSO BRASILEIRO DE MICROBIOLOGIA, 20, 1999, Salvador-Ba. Resumos ... Salvador-Ba: Sociedade Brasileira de Microbiologia, 1999, p. 368.

[28] ROSA, V.; GRANADA, G. G.; ZAMBIAZI, R. C.; Caracterização física e química de granolas. In: $9^{\circ}$ CONGRESSO DE INICIAÇÃO CIÊNTIFICA / $2^{\circ}$ ENCONTRO DA PÓS GRADUAÇÃ̃O - UFPEL, FURG, UCPEL, Pelotas - RS, 2000. Resumos ...: Pelotas - RS, v. 2, p. 715.

[29] SIMÕES, A. M. M.; FURTUNATO, D. M. N.; SILVA, M. D.; SANTOS, N. S.; MAZZA, R. P. D. Elaboração, valor nutritivo e vida de prateleira granola. In: CONGRESSO BRASILEIRO DE CIÊNCIA E TECNOLOGIA DE ALIMENTOS, 17, Fortaleza-CE, 2000. Resumos ... Fortaleza-CE: Sociedade Brasileira de Ciência e Tecnologia de Alimentos, 2000, v. 3, p.7.31.

[30] SIQUEIRA, R. S. Manual de microbiologia de alimentos. Embrapa, 1995. 159p.

[31] STATSOFT - Statisitica. Tulsa: Statisoft, v 1, 1991, 935p.

[32] TORREZAN, R.; EIROA, M. N. U.; PFENNING, L. Identificação de microrganismos isolados em frutas, polpas e ambiente industrial, Boletim do CEPPA, Curitiba, v. 18, n. 1, p. 27-38, jan./jun. 2000.

[33] VANDERZANT, C.; SPLITTSTOESSER, D.F. Compendium for the Microbilogical Examination of Foods. 3 ed. Washington: Public Health Association, 1992, 1219 p.

[34] VALENTE, S. L. M., FURLANI, R. P. Z. Survey of aflatoxins, ochratoxin A, zearalenone, and sterigmatocystin in health foods and breakfast cereals commercialized in the city of campinas, São Paulo. Ciência e Tecnologia de Alimentos, v.16, n. 2, p. 126-129, 1996. 